\title{
Real-time Observation of Sintering Process of Carbon Supported Platinum Nanoparticles in Oxygen and Water through Environment TEM
}

\author{
Langli Luo ${ }^{1}$, Yuyan Shao ${ }^{2}$ and Chongmin Wang ${ }^{1}$ \\ ${ }^{1}$ Environmental Molecular Sciences Laboratory, Pacific Northwest National Laboratory, Richland, WA, \\ USA \\ ${ }^{2}$ Energy and Environment Directorate, Pacific Northwest National Laboratory, Richland, WA, USA
}

Sintering of Pt electrocatalyst largely determines the life-time of PEM fuel cells. While extensive efforts have been made to increase the durability and explore the sintering mechanism of carbon supported Pt NPs, the real behaviors of Pt catalysts in working ambient of PEM fuel cells remain elusive. It has long been recognized that deactivation of the Pt-based electrocatalyst is directly related to the coarsening of the Pt nanoparticles under working conditions of PEMFC ${ }^{1,2}$. In situ TEM is inherently an effective and straightforward technique to visualize the sintering process and reveal the mechanisms of the sintering process of Pt NPs.

Herein, we use aberration corrected environmental transmission electron microscopy to observe the dynamics of Pt catalyst in fuel cell relevant gas conditions. We found the sintering of Pt NPs proceeded through migration and coalescence process, whose rate was largely affected by different gas environment (e.g. $\mathrm{O}_{2}$ and $\mathrm{H}_{2} \mathrm{O}$ ). As compared with the case of $\mathrm{H}_{2} \mathrm{O}, \mathrm{O}_{2}$ promotes $\mathrm{Pt}$ nanoparticle migration on carbon surface as shown in Figure 1. The strong oxygen chemisorption on Pt nanoparticles weakens the interaction between $\mathrm{Pt}$ and CNT surface ${ }^{3}$, leading to a fast migration in $\mathrm{O}_{2}$. These results provide direct observations of dynamics of metal nanoparticles at critical surface under relevant conditions and yield significant insights into the multi-phase interaction in related technological processes.

\section{Reference:}

[1] Wilson, M. S., et al, J. Electrochem. Soc. 140, 2872-2877 (1993).

[2] Ferreira, P. J. et al. Instability of Pt/C Electrocatalysts in Proton Exchange Membrane Fuel Cells: A Mechanistic Investigation. J. Electrochem. Soc. 152, A2256-A2271 (2005).

[3] Getman, R. B., Xu, Y. \& Schneider, W. F. Thermodynamics of Environment-Dependent Oxygen Chemisorption on Pt(111). J. Phys. Chem. C 112, 9559-9572 (2008). 


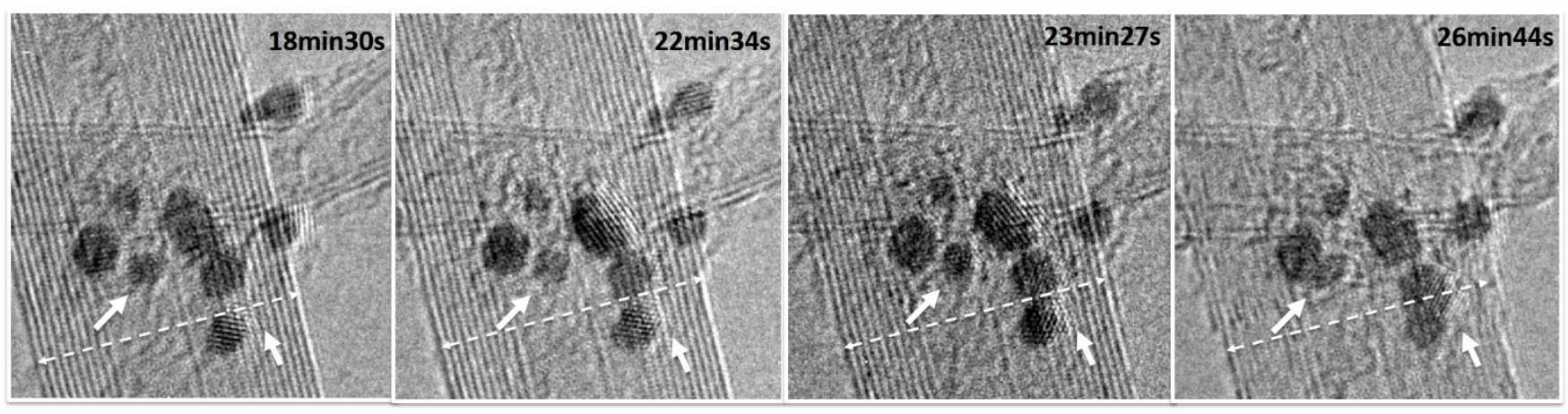

Figure 1 | Coarsening process of Pt/CNTs in $\mathrm{O}_{2}$ gases at $100{ }^{\circ} \mathrm{C}$. A series of time-lapse HRTEM images reveal the coarsening of Pt nanoparticles supported on CNTs is dominated by the migration and coalescence process.
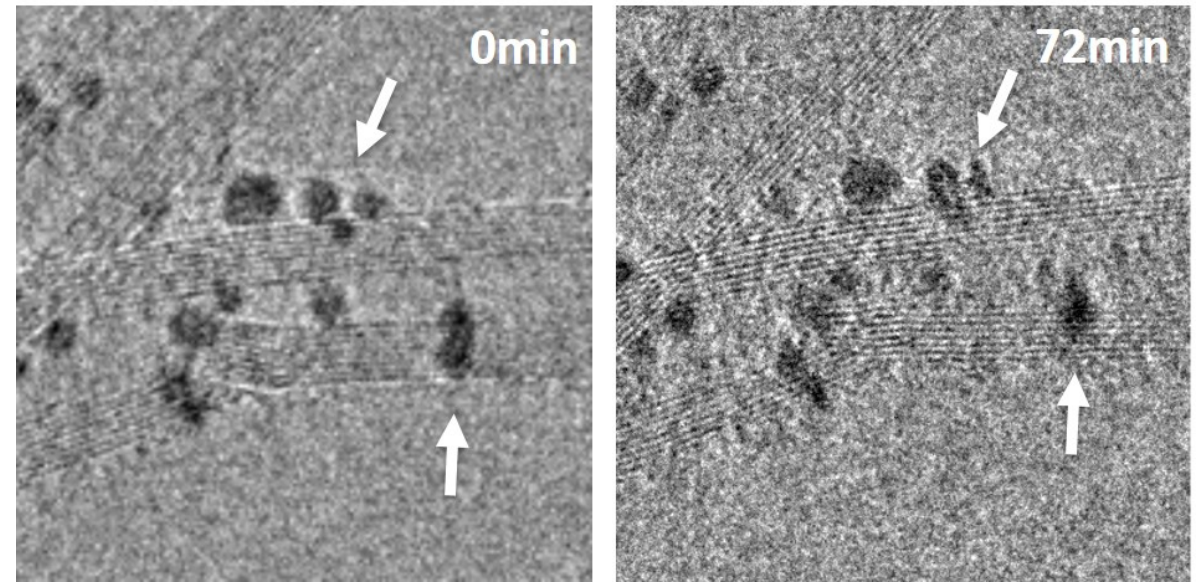

Figure 2 | Coarsening process of Pt/CNTs in $\mathrm{H}_{2} \mathrm{O}$ gases at $100{ }^{\circ} \mathrm{C}$. Time-lapse HRTEM images reveal the migration of $\mathrm{Pt}$ nanoparticles supported on CNTs in $\mathrm{H}_{2} \mathrm{O}$ is much slower than that in $\mathrm{O}_{2}$. 